\title{
Streamflow responses to climate change and $L U C C$ in a semi-arid watershed of Chinese Loess Plateau
}

\author{
LI Qingyun ${ }^{1}$, SUN Yanwei ${ }^{1}$, YUAN Wenlin ${ }^{2 *}$, LYU Subing $^{1}$, WAN Fang ${ }^{1}$ \\ ${ }^{1}$ School of Water Conservancy, North China University of Water Resources and Electric Power, Zhengzhou 450046, China; \\ ${ }^{2}$ School of Water Conservancy and Environment, Zhengzhou University, Zhengzhou 450001, China
}

\begin{abstract}
Climate change and Land Use/Cover Change (LUCC) have been identified as two primary factors affecting watershed hydrological regime. This study analyzed the trends of streamflow, precipitation, air temperature and potential evapotranspiration (PET) from 1962 to 2008 in the Jihe watershed in northwestern Loess Plateau of China using the Mann-Kendall test. The streamflow responses to climate change and LUCC were quantified independently by the elasticity method. The results show that the streamflow presented a dramatic decline with a turning point occurred in 1971, while the precipitation and PET did not change significantly. The results also show that the temperature rose markedly especially since $1990 \mathrm{~s}$ with an approximate increase of $1.74^{\circ} \mathrm{C}$ over the entire research period (1962-2008). Using land use transition matrix, we found that slope cropland was significantly converted to terrace between 1970s and 1990s and that forest cover increased relatively significantly because of the Grain for Green Project after 2000. The streamflow reduction was predominantly caused by LUCC and its contribution reached up to $90.2 \%$, while the contribution of climate change to streamflow decline was only $9.8 \%$. Although the analytical results between the elasticity method and linear regression model were not satisfactorily consistent, they both indicated that LUCC (human activity) was the major factor causing streamflow decline in the Jihe watershed from 1962 to 2008.
\end{abstract}

Keywords: streamflow; LUCC; climate change; Mann-Kendall test; elasticity method; Loess Plateau

Citation: LI Qingyun, SUN Yanwei, YUAN Wenlin, LYU Subing, WAN Fang. 2017. Streamflow responses to climate change and LUCC in a semi-arid watershed of Chinese Loess Plateau. Journal of Arid Land, 9(4): 609-621. doi: $10.1007 / \mathrm{s} 40333-017-0095-2$

\section{Introduction}

Changes in streamflow reflect the combined effects of climate, vegetation and soil (Rodriguez-Iturbe et al., 2001). Climate and hydrology are intricately linked and the response of hydrological cycle to climate change has been widely investigated by researchers, e.g., Xu et al. (2013), Perazzoli et al. (2013) and Ashraf Vaghefi et al. (2014). Researches consistently unearthed basin-wide rising of temperature, spatial variations of precipitation, and basin-wide decrease in water resources in the Yellow River Basin (Xu et al., 2007; Hu et al., 2011). Li et al. (2011) used four climate models with the prescribed three emission scenarios to assess the impact of future climate changes on hydrology in a tableland region of Loess Plateau, and the modeling predicted $-2.6 \%-17.4 \%$ changes for precipitation and 10\%-130\% changes for streamflow under the three emission scenarios. In brief, examination of precipitation-runoff relationships under various climatic change scenarios can provide the needed scientific references for sustainable water

*Corresponding author: YUAN Wenlin (E-mail: yw12009@zzu.edu.cn)

Received 2016-08-08; revised 2017-01-18; accepted 2017-05-25

(C) Xinjiang Institute of Ecology and Geography, Chinese Academy of Sciences, Science Press and Springer-Verlag Berlin Heidelberg 2017 
resources management.

Apart from the climate variability, Land Use/Cover Change (LUCC) induced by human activities (e.g., agriculture, industrialization, urbanization, ecosystem conservation and reservoir building) also influence regional hydrology regime (Cuo et al., 2013) and could profoundly alter the hydrological characteristics. For example, planting trees and grasses can alter the water balance of a catchment through increasing precipitation interception and enhancing evapotranspiration (Brown et al., 2005). Nunes et al. (2011) studied hydro-geomorphic responses between different land use and land cover types and found that vegetation dynamic was the key factor in modulating the hydrological responses to LUCC in a marginal region of Portugal. In addition, land reclamation and management changes, especially extensive channel engineering, were found to be more important than climatic variation in causing the observed increasing river runoff in some regions (Schilling et al., 2010). On the Chinese Loess Plateau, the comprehensive practices have been carried out to control severe soil erosion in the past 30 years, including afforestation, building terraces and check dams. Reservoirs were built for both irrigation and drinking water supply with an additional aim to mitigate soil and water losses through reducing surface runoff.

Interactions between LUCC and regional climate variations are important in controlling watershed hydrological processes. The impacts of climate change and LUCC on hydrological regime are actually theoretically interlinked and therefore cannot be completely separated. Liu et al. (2003) concluded that climate change was the major reason for the total runoff decline while the land cover change was a minor reason in the Yellow River source region in 1980s and 1990s. The Loess Plateau, located in northwest China, has attracted much attention because of highly erodible loessial soils, steeply-sloped landscape, frequent rainfall storms, and low vegetation cover (Li et al., 2010; Fan et al., 2015). A study in Wudinghe watershed found that the contributions of climate change and human activities to streamflow decline were $35 \%$ and $65 \%$, respectively. Channel (e.g., check-dam) and slope measures (e.g., terrace) and the Grain for Green Project were identified as the dominant factors responsible for the streamflow decline (Liang et al., 2015). Another study on the Loess Plateau in Shanxi Province attributed the streamflow reduction to increased forest cover and concluded that the effects of LUCC and climate change on streamflow reduction were $53.2 \%$ and $46.8 \%$, respectively (Tang et al., 2010). These conclusions were drawn from the different studies that covered different periods using different methods. Further researches are thus necessary for improving the understanding of combined effects of climate change and LUCC on streamflows.

Numerous methods have been developed for estimating the impacts of climatic change and LUCC on streamflow and these methods include climate models coupled with spatially-distributed hydrological models (Chen et al., 2005; Li et al., 2013; Al-Mukhtar et al., 2014; Fiseha et al., 2014). However, climate models are always a result of downscaling regional climate models or globe climate model and the coarse resolution cannot capture geographical details precisely. Therefore, they may not provide full representation of variables to the scale required by hydrological models. Consequently, coupling climate models with hydrological models bring great uncertainties. Alternatively, methods that use the observed meteorological and hydrological data and that use the interpolator of an appropriate form based on simple theories (e.g., water balance and Budyko hypothesis) can be more realistic for estimating the impacts of climatic change and LUCC on streamflow. Zhang et al. (2001) developed a conceptual model based on catchment water balance, which can assess the long-term effects of vegetation cover changes on evapotranspiration and other hydrological factors. Xu et al. (2014) and Yang et al. (2014), both based on the Budyko framework, estimated the streamflow responses to climate change using an elasticity method. Studies repeatedly showed that this simple model performed well and was potentially useful for investigating the watershed hydrological responses to environmental changes.

This study investigated the trends of climate variables and streamflow in the Jihe watershed for the period of 1962-2008 and the objectives were (1) to detect the statistical variability trends in meteorological and hydrological regimes; (2) to identify the abrupt turning points; and (3) to 
search for the dominant factors (climate change or human activity). The research results would be of significance for water resources management.

\section{Research watershed}

The Jihe watershed is located in Tianshui, a city of Gansu Province in China $\left(34^{\circ} 20^{\prime} 19^{\prime \prime}-\right.$ $34^{\circ} 38^{\prime} 59^{\prime \prime} \mathrm{N}, 105^{\circ} 07^{\prime} 50^{\prime \prime}-106^{\circ} 00^{\prime} 45^{\prime \prime} \mathrm{E}$; 1158 to $2699 \mathrm{~m}$ a.s.l.; Fig. 1). The catchment area is 1019 $\mathrm{km}^{2}$ and the branch stream is $61 \mathrm{~km}$ long. The mean annual precipitation is about $556 \mathrm{~mm}$ with the most falling in summer. The air temperature has large diurnal but small seasonal variations with an annual mean of $10.8^{\circ} \mathrm{C}$. The land uses are predominantly croplands and grasslands. The watershed is mainly covered by cinnamon soil, loessal soil and alluvial soil, and terracing is the main soil conservation measure. Revegetation and pasture establishment have been implemented in the Jihe watershed to improve the eco-environment.

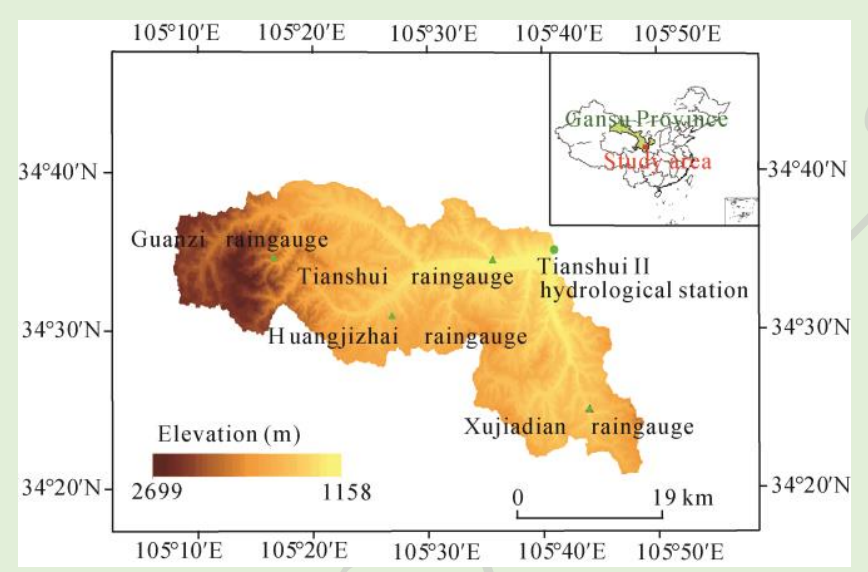

Fig. 1 Sketch map of the Jihe watershed in Gansu Province, China

\section{Data and methodology}

\subsection{Data collection}

The daily streamflow data of Tianshui II hydrological station and the daily precipitation observation data of the four raingauge stations (Huangjizhai, Guanzi, Xujiadian and Tianshui; Fig. 1) for the study period were obtained from Chinese Hydrologic Data Yearbook. The air temperature, sunshine hours, relative humidity and wind speed were downloaded from the National Meteorological Information Centre of China Meteorological Administration (http://data.cma.cn/site/index.html). The watershed mean annual precipitation was computed by Thiessen polygon method.

Four satellite images, Landsat MSS (1975), Landsat TM (1990, 2000), and Landsat ETM+ (2008), were acquired from the Institute of Geographic Sciences and Natural Resources Research, Chinese Academy of Sciences. We processed the images based on geospatial analysis platform in ArcGIS 9.2 to identify the land cover categories. Land use maps of the four periods $(1975,1990$, 2000,2008 ) were used to assess the impact of LUCC on hydrologic regime. According to the field investigation on geomorphologic features from April to September in 2009, combining with the measured data on soil and vegetation cover types in the hilly region of Loess Plateau, seven land use types were identified as forest, grassland, slope cropland, terrace, settlement, unused land, and water body.

\subsection{Methods}

3.2.1 Trend test of hydroclimatic variables

Based on the major (or abrupt) change point of the streamflow, we divided the meteorological and hydrological data series into the baseline period (before the change point) and the post-change 
period (after the change point). We assumed that there was no human interference in the baseline period. The potential evapotranspiration (PET) was estimated by Hargreaves equation that used the easily obtainable data including daily average, maximum and minimum air temperatures, and extraterrestrial radiation (Berti et al., 2014). The non-parametric Mann-Kendall (M-K) test and the moving T-test were combined to detect trends in hydroclimatic time series. The test statistic sequence UF is estimated by the sequential data series while the backward sequence UB is estimated by the inversed data series. The intersection point of UF and UB located between the confidence interval is the time when an abrupt change or a change point occurred in the M-K test (Zhang et al., 2013). The details about the two tests can be seen in Chen et al. (2010), Myronidis et al. (2012), and Yang et al. (2014).

\subsubsection{Climate elasticity method}

The elasticity coefficient, which was firstly proposed by Schaake (1990) and subsequently improved by others, is defined as the ratio of the streamflow variation rate to the variation rate of a certain climatic factor (precipitation or PET; Eq. 1).

$$
\varphi_{X}=\frac{\partial Q / Q}{\partial X / X}, \text { or } \frac{\partial Q}{\partial X}=\varphi_{X} \frac{Q}{X},
$$

where $\varphi_{X}$ is the streamflow elasticity coefficient to climatic factors, $Q$ is the annual average streamflow $(\mathrm{mm})$, and $X$ is a certain climatic factor. An analytical method, deriving climate elasticity of streamflow based on Budyko hypothesis, is well defined in theory and does not depend on a large amount of historical data, and consequently it has been applied in many studies (Yang and Yang, 2011). Equation 2 formulated by Zhang et al. (2001) has been used most.

$$
\frac{E}{P}=\frac{1+w \frac{E_{0}}{P}}{1+w \frac{E_{0}}{P}+\left(\frac{E_{0}}{P}\right)^{-1}},
$$

where $E, P$ and $E_{0}$ are the mean annual evapotranspiration, precipitation, and PET, respectively. The parameter $w$ describes the watershed characteristics of the combined underlying surface such as land cover, soil type and vegetation. Given $P, Q$ and $\mathrm{E}_{0}$, the parameter $w$ is estimated by Equation 2 through minimizing the difference between modelled $E$ and $E$ calculated from watershed water balance. Assuming the response of the streamflow to the climatic factors is principally caused by precipitation and PET, the changes in mean annual streamflow due to climate variability $\left(\Delta Q^{\text {clim }}\right)$ can be calculated by Equation 3 through the complete differential theory (Milly and Dunne, 2002; Zhan et al., 2014).

$$
\Delta Q^{\text {clim }}=\varphi_{P} \Delta P+\varphi_{E_{0}} \Delta E_{0},
$$

where $\Delta Q^{\text {clim }}$ is the changes in annual streamflow due to climate variability, $\Delta P$ and $\Delta E_{0}$ are the changes in annual precipitation and PET, respectively; $\varphi_{p}$ is the precipitation elasticity of streamflow (Eq. 4) and $\varphi_{E_{0}}$ is the PET elasticity of streamflow (Eq. 5).

$$
\begin{gathered}
\varphi_{P}=\frac{1+2 \frac{E_{0}}{P}+3 w\left(\frac{E_{0}}{P}\right)^{2}}{\left[1+\frac{E_{0}}{P}+w\left(\frac{E_{0}}{P}\right)^{2}\right]^{2}}, \\
\varphi_{E_{0}}=-\frac{1+2 w \frac{E_{0}}{P}}{\left[1+\frac{E_{0}}{P}+w\left(\frac{E_{0}}{P}\right)^{2}\right]^{2}},
\end{gathered}
$$


where $E_{0} / P$ is the aridity index.

3.2.3 Separating the effect of climate change from the effect of LUCC on streamflow

For a given catchment, changes in streamflow can be attributed by the coupling effects of all human activities and climate parameters (precipitation and potential evapotranspiration induced). We assume that the total streamflow change $\left(\Delta Q^{\text {tot }}\right)$ could be partitioned into these two factors (human and climate) and can be calculated by Equation 6 .

$$
\Delta Q^{\mathrm{tot}}=\Delta Q^{\mathrm{clim}}+\Delta Q^{\mathrm{LuCC}}
$$

where $\Delta Q^{\mathrm{LUCC}}$ is the changes in annual streamflow due to LUCC, $\Delta Q^{\text {tot }}$ can be calculated by the following equation:

$$
\Delta Q^{\mathrm{tot}}=\bar{Q}_{2}-\bar{Q}_{1},
$$

where $\bar{Q}_{1}$ and $\bar{Q}_{2}$ are the observed mean annual streamflow before and after the change point respectively, which can be determined and identified by the M-K test after the change point. Then the $\Delta Q^{\text {tot }}$ subtracts the result of Equation 3 and the response of streamflow to LUCC $\left(\Delta Q^{\mathrm{LUCC}}\right)$ can be assessed through Equation 6.

\section{Results}

\subsection{Changes in streamflow}

Figure 2 shows the hydrograph for the period 1962-2008. It exhibited a significant and monotonous decreasing trend at a slope of $-2.48 \mathrm{~mm} / \mathrm{a}$. The coefficient of variation reached about $75 \%$, presenting rather large fluctuations over the 47 -year study period. The average annual streamflow depth was $76 \mathrm{~mm}$, and the maximum and minimum levels were $247.3 \mathrm{~mm}$ (1967) and $1.7 \mathrm{~mm}$ (1996), respectively. The average annual streamflow of the 1990s declined dramatically, only accounted for $43.1 \%$ of the mean annual of the study period. This was caused by the reduction in precipitation and the impact of LUCC. As seen in Figure 3a, annual cumulative anomaly streamflow fluctuated frequently since the middle 1970s and there were two major (or abrupt) change points occurred: one in 1974 and another in 1982. According to the M-K test (Fig. $3 b)$, the UF statistic showed a downward trend since 1968 . The mean UF series was -2.48 after 1990, apparently lower than the $95 \%$ confidence level of -1.96 .

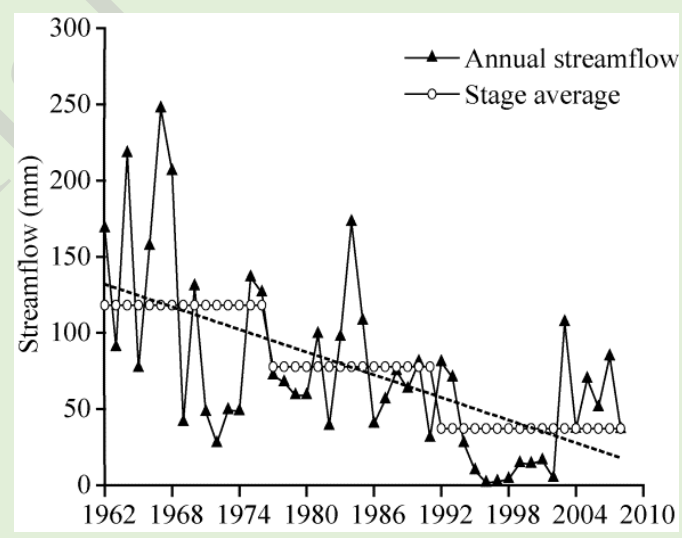

Fig. 2 Average annual streamflow during the period of 1962-2008

There were three intersections appeared in 1971, 1975 and 1976 for UF and UB (Fig. 3b) with the intersection in 1975 dropped out of the lower limit confidence level. Based on the principle that the intersection must be within the confidence lines, it indicated the beginning of an abrupt change. Therefore, the change points took place in 1971 and 1976, signifying that the streamflow exhibited two abrupt changes during the research period. The UF values in the four years between 1972 and $1975(-2.34,-2.47,-2.62$ and -2.14 , respectively) had all surpassed the $95 \%$ 
confidence level, and so it is proper to define 1971 as the change point after which the steamflow significantly declined. Furthermore the statistic value had completely surpassed the 95\% significance level since 1991, demonstrating that the streamflow presented a markedly sharp decline since then.
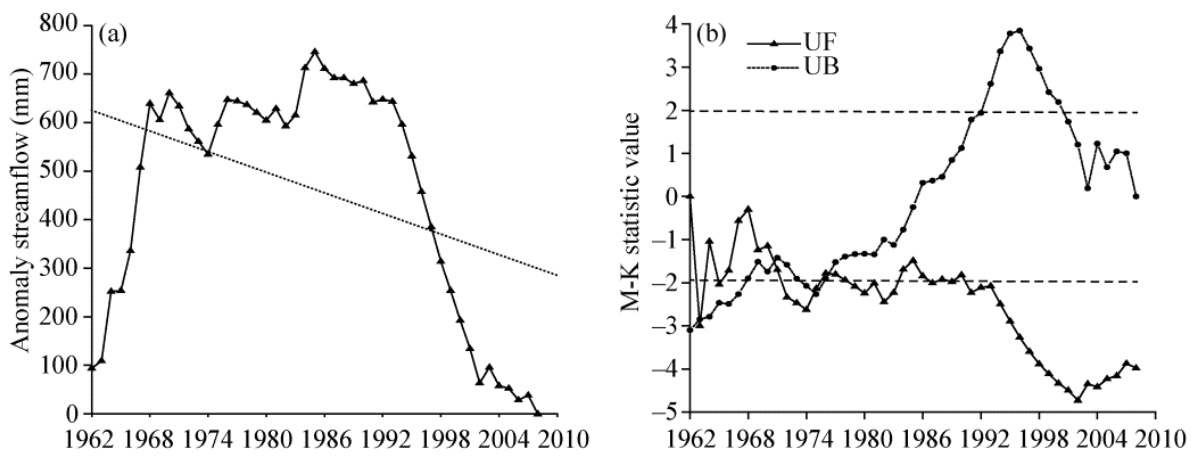

Fig. 3 Annual cumulative anomaly streamflow (a) and the Mann-Kendall (M-K) test of annual streamflow (b) in the Jihe watershed. Horizontal dashed lines in Figure $3 \mathrm{~b}$ indicate the $95 \%$ confidence level.

\subsection{Climate changes and change points}

Figure 4 shows the variations of annual precipitation and PET in the Jihe watershed during 19622008. The decadal mean precipitation was lower in the 1990s than in the other periods. There was no significant fluctuation in precipitation with a linear slope at $-3.0 \mathrm{~mm} / \mathrm{dec}$ ade and PET exhibited a slightly rising linear trend at $11.7 \mathrm{~mm} /$ decade. Besides, as shown in Figure 5, the M-K test and the moving T-test demonstrated that the trends in annual precipitation and PET were not at $95 \%$ significant confidence level. The annual PET presented an increasing trend from the middle 1980s and the trend was also collaborated by the UF statistical value (Fig. 5a) and the moving T-test (Fig. 5b). However, as for annual precipitation, there were differences about the two tests (Figs. 5c and d). The two change points occurred in 1993 and 1994, meaning that the monotonic trend in annual precipitation was statistically significant after 1994.

Annual average temperature rose evidently since 1962 with a linear warming trend at $0.37^{\circ} \mathrm{C} /$ decade (Fig. 6a). Overall, the annual average temperature was increased by $1.74^{\circ} \mathrm{C}$ during the entire research period (1962-2008). A change point occurred in 1993 according to the M-K test (Fig. 6b), indicating the long-term monotonic trend in temperature is statistically significant. Furthermore, the M-K statistic values exceeded the confidence level of $95 \%$ since 1994, meaning that the annual mean temperature in the Jihe watershed presented a distinctive increasing trend during the 15-year period from 1994 to 2008. As for seasonal mean temperature (Fig. 6c), it rose

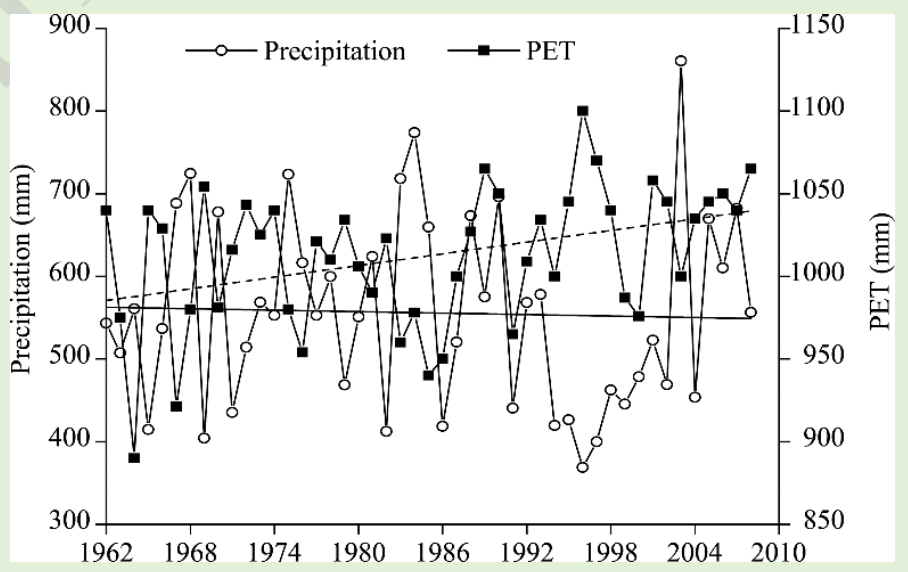

Fig. 4 Long term trends of annual precipitation and potential evapotranspiration (PET) from 1962 to 2008 in the Jihe watershed. Solid line and dotted line represent the linear trend of annual precipitation and PET, respectively. 

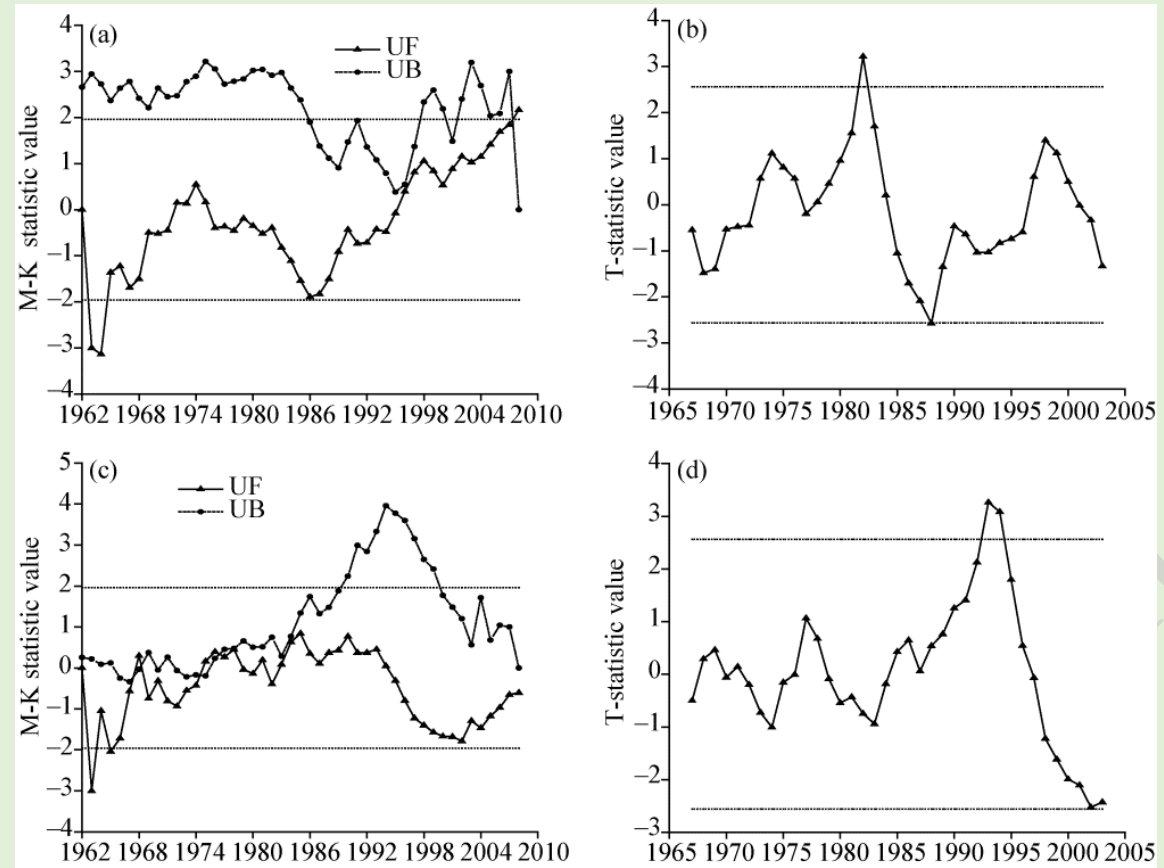

Fig. 5 The M-K test of annual PET (a) and precipitation (c) and the moving T-test of annual PET (b) and precipitation (d) in the Jihe watershed

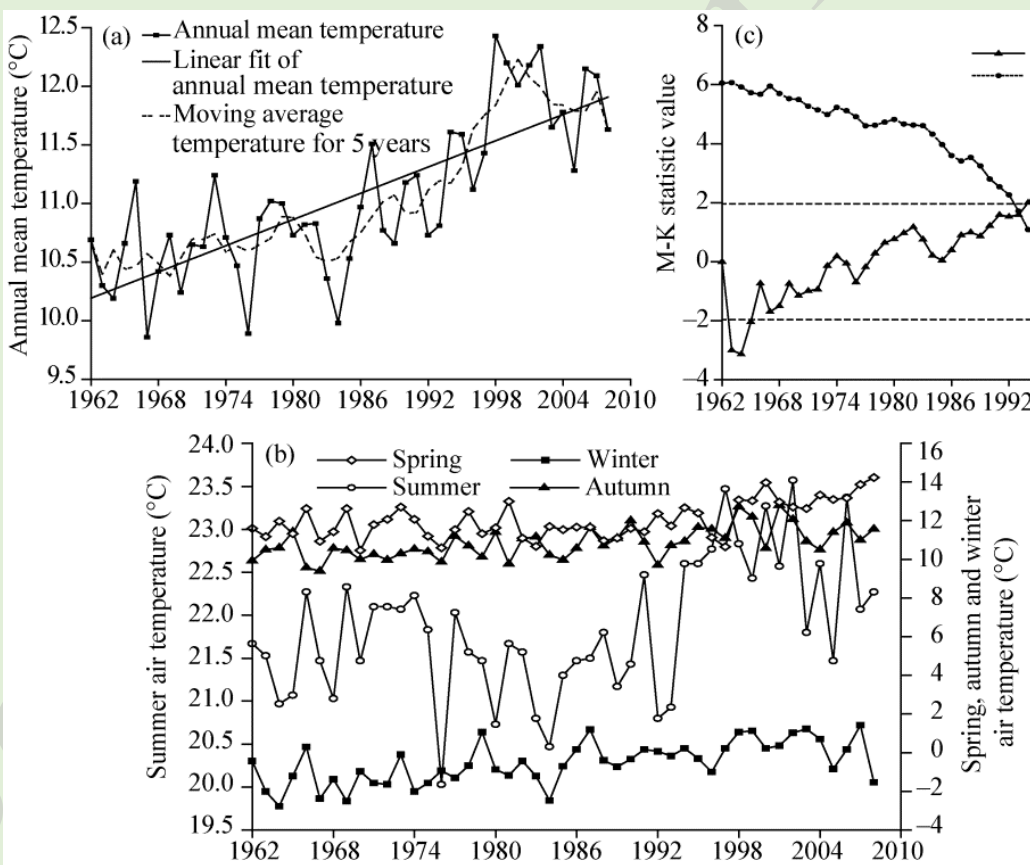

Fig. 6 Variations of annual temperature (a), seasonal temperature (b), and the $\mathrm{M}-\mathrm{K}$ test of annual temperature (c) in the Jihe watershed

more in winter and spring (the linear increasing trend at $0.49^{\circ} \mathrm{C} / \mathrm{decade}$ and $0.37^{\circ} \mathrm{C} / \mathrm{dec}$ ade, respectively) than in summer and autumn (the linear increasing trend at $0.27^{\circ} \mathrm{C} / \mathrm{decade}$ and $0.34^{\circ} \mathrm{C} /$ decade, respectively).

\subsection{LUCC in the Jihe watershed}

Land use types of the Jihe watershed for 1975, 1990, 2000 and 2008 are presented in Table 1. In 
1975 , the slope cropland and grassland occupied nearly $80 \%$ of the total watershed, whereas the terrace only accounted for $6.5 \%$ (Fig. 7). From 1975 to 1990, the terrace was rapidly increased by $397.1 \%$ from 66.3 to $329.6 \mathrm{~km}^{2}$ and the slope cropland was reduced dramatically by $65.7 \%$. The forest land, water body and settlement all declined slightly. With the implement of the Grain for Green Project in 1998, the forest cover increased steadily. The terrace, forest and grassland accounted for $87.8 \%$ of the watershed, and the three types (terrace, forest and grassland) were the predominant land use types in the Jihe watershed. It should be noted that the area of slope cropland was reduced by $77.2 \%$ over the research period and the area of terrace cropland was increased by more than four times with the largest changes occurred in 1975-1990. The areas of the other five land use types had relatively small variations (Fig. 7).

Table 1 Temporal changes of Land Use/Cover Change in the Jihe watershed

\begin{tabular}{|c|c|c|c|c|c|c|c|c|}
\hline \multirow{2}{*}{ Land use type } & \multicolumn{4}{|c|}{ Area $\left(\mathrm{km}^{2}\right)$} & \multicolumn{4}{|c|}{ Changes (\%) } \\
\hline & 1975 & 1990 & 2000 & 2008 & 1975-1990 & 1990-2000 & 2000-2008 & 1975-2008 \\
\hline Slope cropland & 407.4 & 139.7 & 102.0 & 92.8 & -65.7 & -30.0 & -9.0 & -77.2 \\
\hline Terrace & 66.3 & 329.6 & 337.1 & 346.3 & 397.1 & 2.3 & 2.7 & 422.3 \\
\hline Forest & 116.6 & 110.7 & 132.1 & 142.1 & -5.1 & 19.3 & 7.6 & 21.9 \\
\hline Grassland & 398.2 & 411.0 & 418.1 & 406.5 & 3.2 & 1.7 & -2.8 & 2.1 \\
\hline Settlement & 25.3 & 23.1 & 24.5 & 26.6 & -8.7 & 6.1 & 8.6 & 5.1 \\
\hline Water body & 2.6 & 2.2 & 2.4 & 2.0 & -15.4 & 9.1 & -16.7 & -23.1 \\
\hline Unused land & 2.7 & 2.7 & 2.8 & 2.7 & 0.0 & 3.7 & -3.6 & 0.0 \\
\hline
\end{tabular}

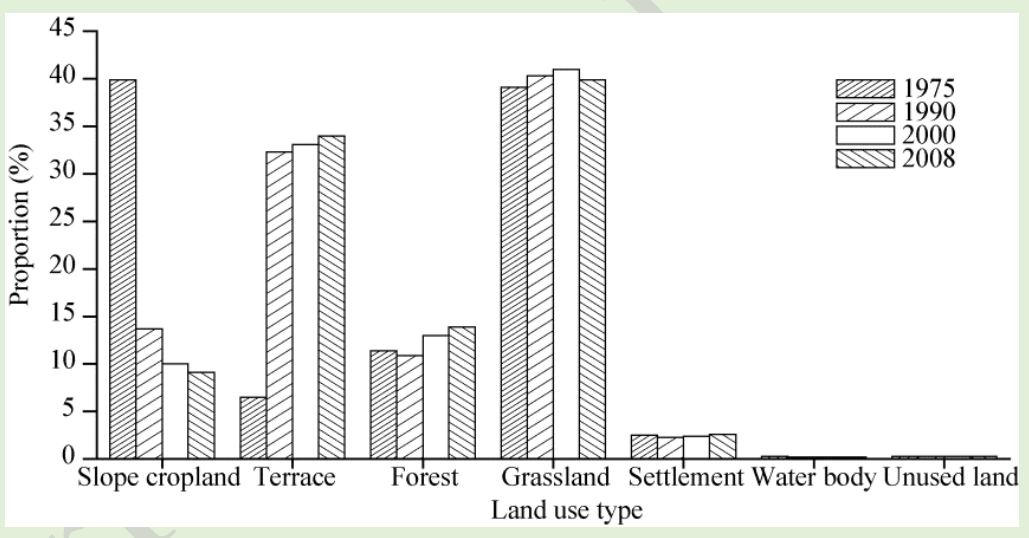

Fig. 7 Histogram on the proportion changes for the land use types

The land use transition matrix showed the inter-conversions among the land use types and reflected the dynamic processes of the LUCC. The four-period land use maps were fused using the dissolve tool of ArcMap to merge into one land use record to enhance the computation efficiency. The unchanged area and converted area for a land use type were calculated using the superposition function of the ArcGIS spatial analysis, and the land use transition matrixes in 1975-1990, 1990-2000, 2000-2008 and 1975-2008 were then obtained. The results were listed in Tables 2 and 3 and also shown in Figures 8 and 9. Table 2 shows that the main transition was the conversion of slope cropland to terrace cropland and grassland, the flow-out probability of slope cropland reached $78.8 \%$, with $71.6 \%$ to terrace, $6.2 \%$ to grassland, and $1.0 \%$ to forest and settlement. Both forest and grassland showed very small conversions during 1975-1990, with the flow-out probabilities of $6.0 \%$. The inter-conversions of land use types have been relatively small since 1990s (Table 3). Along with the Grain for Green Project, some terraces and slope croplands were transferred to forest and grassland. The period of 2000-2008 was the time period when the land use types had the smallest changes (Fig. 8). 
Table 2 Transition matrix of land use types in 1975-1990 in the Jihe watershed

\begin{tabular}{|c|c|c|c|c|c|c|c|c|}
\hline \multirow{3}{*}{\multicolumn{2}{|c|}{ Land use type }} & \multicolumn{7}{|c|}{1990} \\
\hline & & Slope cropland & Forest & Grassland & Water body & Settlement & Unused land & Terrace \\
\hline & & \multicolumn{7}{|c|}{$\left(\mathrm{km}^{2}\right)$} \\
\hline \multirow{7}{*}{1975} & Slope cropland & 86.18 & 1.70 & 25.37 & 0.41 & 2.21 & 0.00 & 291.74 \\
\hline & Forest & 1.48 & 96.10 & 2.76 & 0.00 & 0.03 & 0.00 & 1.87 \\
\hline & Grassland & 6.83 & 8.52 & 388.83 & 0.00 & 0.35 & 0.09 & 11.83 \\
\hline & Water body & 0.00 & 0.00 & 0.00 & 2.49 & 0.34 & 0.00 & 0.14 \\
\hline & Settlement & 1.73 & 0.03 & 0.67 & 0.00 & 21.54 & 0.00 & 3.29 \\
\hline & Unused land & 0.00 & 0.00 & 0.09 & 0.00 & 0.00 & 2.61 & 0.00 \\
\hline & Terrace & 2.80 & 0.13 & 7.95 & 0.00 & 0.05 & 0.00 & 37.79 \\
\hline
\end{tabular}

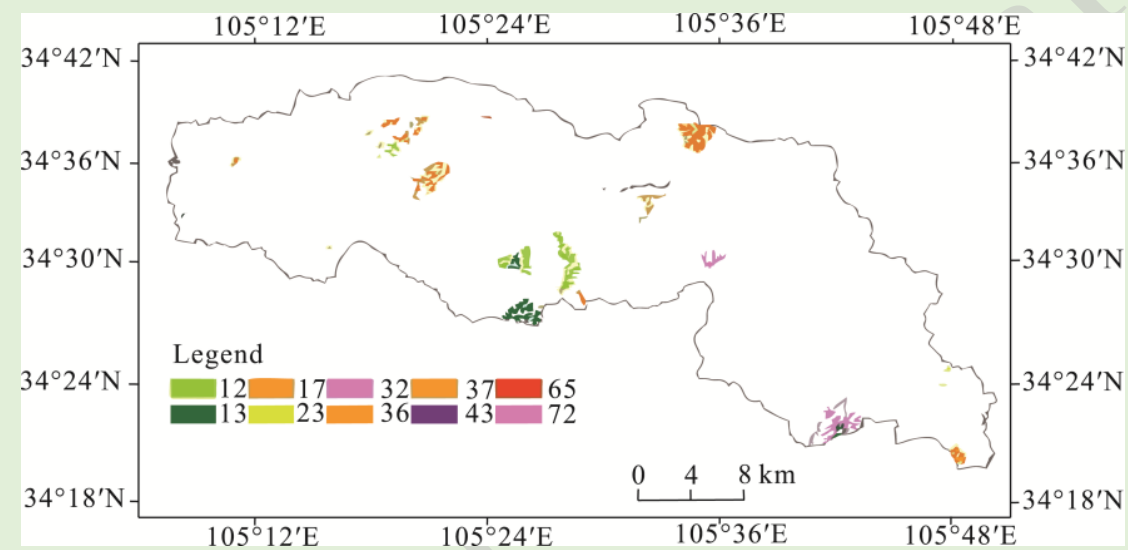

Fig. 8 Transition matrix map of land use types in 2000-2008 in the Jihe watershed. The numbers from 1 to 7 symbolize slope cropland, forest, grassland, water body, settlement, unused land and terrace, respectively. Different figure combination expressed the conversions of two land use types. For example, 12 indicates the conversion of slope cropland to forest, etc.

Table 3 Transition matrix of land uses in 1990-2000 in the Jihe watershed

\begin{tabular}{|c|c|c|c|c|c|c|c|c|}
\hline \multirow{3}{*}{\multicolumn{2}{|c|}{ Land use type }} & \multicolumn{7}{|c|}{2000} \\
\hline & & Slope cropland & Forest & Grassland & Water body & Settlement & Unused land & Terrace \\
\hline & & \multicolumn{7}{|c|}{$\left(\mathrm{km}^{2}\right)$} \\
\hline \multirow{7}{*}{1990} & Slope cropland & 92.92 & 14.23 & 6.33 & 0.00 & 0.66 & 0.00 & 25.56 \\
\hline & Forest & 0.77 & 102.85 & 6.50 & 0.00 & 0.07 & 0.00 & 0.51 \\
\hline & Grassland & 1.63 & 4.06 & 404.10 & 0.00 & 0.59 & 0.00 & 1.64 \\
\hline & Water body & 0.00 & 0.00 & 0.00 & 2.04 & 0.00 & 0.13 & 0.03 \\
\hline & Settlement & 0.29 & 0.08 & 0.50 & 0.00 & 20.22 & 0.00 & 2.01 \\
\hline & Unused land & 0.00 & 0.00 & 0.09 & 0.00 & 0.00 & 2.71 & 0.00 \\
\hline & Terrace & 11.83 & 5.72 & 1.70 & 0.03 & 2.95 & 0.00 & 307.37 \\
\hline
\end{tabular}

Figure 9 further demonstrated the inter-conversions of land use types over the entire study period 1975-2008. The conversions mainly occurred in the middle and lower reaches of the Jihe watershed. The slope cropland declined continuously with $350 \mathrm{~km}^{2}$ being converted to the other land use types. The flow-out probability reached $85.7 \%$ with $74.5 \%$ to terrace and $8.0 \%$ to grassland. In short, slope cropland, terrace and forest were the land use types that had large portions of inter-conversions, and grassland remained relatively stable. 


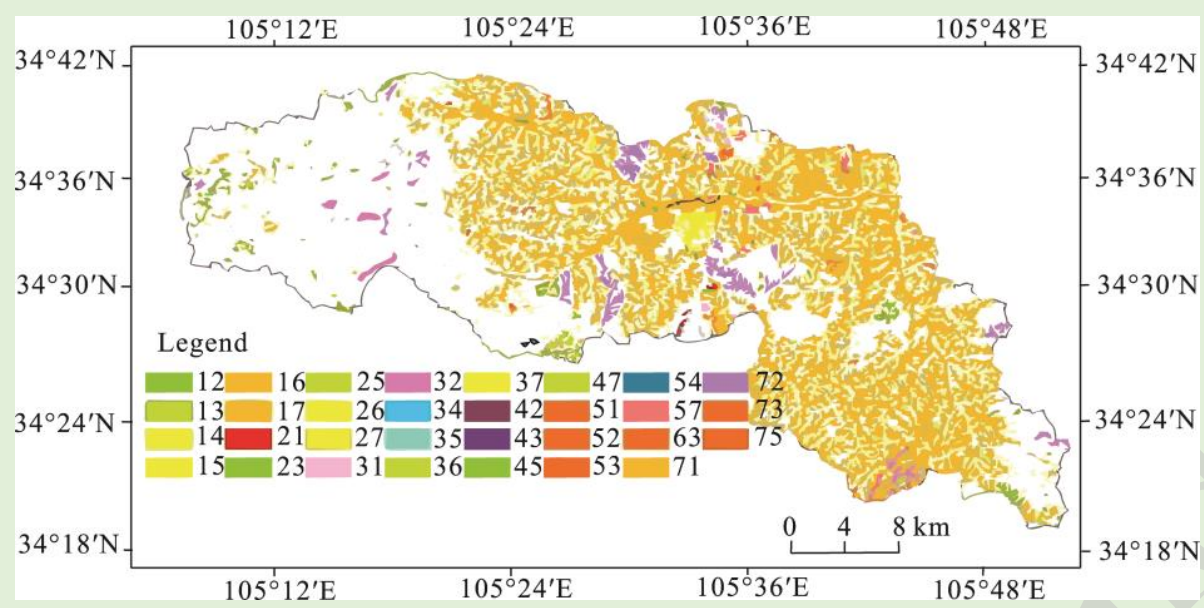

Fig. 9 Transition matrix map of land uses in 1975-2008 in the Jihe watershed

\subsection{Quantifying the effects of climate change and LUCC on streamflow}

The mean, standard deviation (SD), coefficient of variation (CV) and extreme ratio (ER) of climatic factors and streamflow were summarized for the baseline period and also for the post-change period (Table 4). Average annual stramflow was reduced by $52.2 \%$ in the post-change period than that in the baseline period. The CV and ER in the post-change period were also much higher than those in the baseline period. ER in the post-change period (19722008) achieved 103.3, indicating that the streamflow during this period was more discrete and underwent more dramatic changes. Annual precipitation did not present evident changes since the above four statistical parameters were similar in the two periods. Table 5 shows the contributions of climatic change and LUCC to streamflow variations estimated using the elasticity method. The climatic change and LUCC accounted for $9.8 \%$ and $90.2 \%$, respectively, demonstrating that the effect of human activities on hydrological regime was far more important than the climate

Table 4 Annual summary statistics for the baseline period (1962-1971) and post-change period (1972-2008)

\begin{tabular}{|c|c|c|c|c|}
\hline \multirow{2}{*}{ Items } & \multirow[t]{2}{*}{ 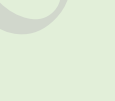 } & Precipitation & Streamflow & Temperature \\
\hline & & $(\mathrm{mm})$ & $\left(\mathrm{m}^{3} / \mathrm{s}\right)$ & $\left({ }^{\circ} \mathrm{C}\right)$ \\
\hline \multirow{5}{*}{ Baseline $\mathrm{p}$} & Mean & 549.3 & 3.87 & 10.49 \\
\hline & SD & 115.8 & 2.05 & 0.37 \\
\hline & CV (\%) & 21.1 & 52.8 & 3.5 \\
\hline & ER & 1.8 & 5.6 & 1.1 \\
\hline & Mean & 557.6 & 1.85 & 11.20 \\
\hline \multirow{3}{*}{ Post-change } & SD & 116.3 & 1.29 & 0.65 \\
\hline & $\mathrm{CV}(\%)$ & 20.9 & 70.1 & 5.9 \\
\hline & ER & 2.3 & 103.3 & 1.3 \\
\hline
\end{tabular}

Note: SD, standard deviation; CV, coefficient of variation; ER, extreme ratio.

Table 5 Contributions of climatic change and LUCC to streamflow

\begin{tabular}{|c|c|c|c|c|c|c|c|c|}
\hline \multirow{2}{*}{ Period } & $P$ & $E_{0}$ & $Q$ & $\Delta Q^{\text {tot }}$ & $\Delta Q^{\text {clim }}$ & $\Delta Q^{\mathrm{LUCC}}$ & $\Delta Q^{\text {clim }}$ & $\Delta Q^{\mathrm{LUCC}}$ \\
\hline & \multicolumn{6}{|c|}{$(\mathrm{mm})$} & \multicolumn{2}{|c|}{$(\%)$} \\
\hline $1962-1971$ & 557.6 & 992.5 & 120.2 & \multirow{2}{*}{63.1} & \multirow{2}{*}{6.2} & \multirow{2}{*}{56.9} & 00 & \multirow{2}{*}{90.2} \\
\hline $1972-2008$ & 549.3 & 1017.8 & 57.1 & & & & 9.0 & \\
\hline
\end{tabular}

Note: $P$, precipitation; $E_{0}$, potential evapotranspiration; $Q$, annual average streamflow; $\Delta Q^{\text {tot }}$, the total streamflow change; $\Delta Q^{\text {clim }}$, the changes in annual streamflow due to climate variability; $\Delta Q^{\mathrm{LUCC}}$, the changes in annual streamflow due to LUCC. 
change in the watershed. Wang et al. (2006) concluded that $35.9 \%$ of total annual streamflow reduction occurred in 1970-1999 was contributed by the climate change and $64.1 \%$ by human activity in the middle reaches of Yellow River, being consistent with the conclusions of this study.

\section{Discussion}

Linear regression model was adopted in the study to compare with the elasticity method. The period division of hydrological series was consistent with the M-K test: the baseline period of 1962-1971 and post-change period of 1972-2008. The relationship between annual precipitation and annual streamflow in the baseline period was built to predict the natural streamflow in the post-change period (Eq. 8).

$$
Y=0.5063 X-139.66(r=0.8055) \text {, }
$$

where $Y$ is the annual streamflow $(\mathrm{mm}), X$ is the annual precipitation $(\mathrm{mm})$, and 0.5063 and -39.66 are regression slope and intercept, respectively (Li et al., 2011).

The simulated value in the post-change period minus the observed value in baseline period was the change in streamflow due to climatic change, and the observed streamflow in the post-change period minus the simulated value in the post-change period was the change in streamflow due to LUCC. Table 6 shows the responses of streamflow to climate change and LUCC. The contribution of LUCC to streamflow reduction reached $119.2 \%$ in the 1970 s while climate change imposed a counteracting impact on the streamflow decline (i.e., -19.2\%). However, climatic factors contributed $33.1 \%$ to the observed streamflow decline in the 1990s and LUCC contributed $66.9 \%$. Overall, during the period from 1972 to 2008, LUCC contributed $104.8 \%$ to the streamline decline and climate change imposed a counteracting impact on the streamflow decline (i.e., -4.8\%). The relationships among the hydrological elements (precipitation, streamflow, evapotranspiration, etc.) are complex and inconstant, it is thus difficult to adopt a precisely-defined equation to describe the relationships. Consequently the error unavoidably exists when we use regression model to analyze the linearity of precipitation-streamflow relationships.

Table 6 Response of streamflow to climate and LUCC based on linear regression model

\begin{tabular}{|c|c|c|c|c|c|c|c|}
\hline \multirow[b]{2}{*}{ Period } & \multicolumn{3}{|c|}{ Streamflow } & \multicolumn{2}{|c|}{ Climate change } & \multicolumn{2}{|c|}{ LUCC } \\
\hline & $\begin{array}{l}\text { Observed } \\
\text { value }(\mathrm{mm})\end{array}$ & $\begin{array}{c}\text { Simulated } \\
\text { value }(\mathrm{mm})\end{array}$ & $\begin{array}{c}\text { Total } \\
\text { reduction } \\
\text { (mm) }\end{array}$ & $\begin{array}{l}\text { Reduction } \\
\text { (mm) }\end{array}$ & $\begin{array}{c}\text { Contribution } \\
(\%)\end{array}$ & $\begin{array}{l}\text { Reduction } \\
\text { (mm) }\end{array}$ & $\begin{array}{c}\text { Contribution } \\
(\%)\end{array}$ \\
\hline $1962-1971$ & 138.4 & & - & - & - & - & - \\
\hline 1972-1979 & 73.3 & 150.9 & 65.1 & -12.5 & -19.2 & 77.6 & 119.2 \\
\hline 1980-1989 & 81.0 & 160.0 & 57.4 & -21.6 & -37.6 & 79.0 & 137.6 \\
\hline 1990-1999 & 32.3 & 103.3 & 106.1 & 35.1 & 33.1 & 71.0 & 66.9 \\
\hline $2000-2008$ & 46.8 & 158.3 & 91.6 & -19.9 & -21.7 & 111.5 & 121.7 \\
\hline $1972-2008$ & 57.8 & 142.3 & 80.6 & -3.9 & -4.8 & 84.5 & 104.8 \\
\hline
\end{tabular}

Note: The negative numbers indicate the increases of streamflow.

Precipitation and PET are supposed to be the major meteorological factors that affect streamflow in river basins (Zhan et al., 2014). However, in the Jihe watershed, they changed relatively insignificantly compared to the streamflow, the latter (i.e., streamflow) displaying a remarkable decreasing tendency in 1962-2008. Quantitative assessment proved that LUCC was the major anthropogenic driving force for the streamflow change. Uncertainties of this study were mainly resulted from two aspects. Firstly, change points were identified by the M-K test to have occurred in 1971 and 1976. However, it should be admitted that the period divisions according to the different change points might lead to a slight difference in the assessment results of the contributions of climate change and LUCC to the streamflow. Secondly, although LUCC is the most relevant human activities, the widely-practiced comprehensive soil erosion control measures are also relevant human activities. However, due to the difficulties in data collection, the soil 
erosion control measures were neglected in this study. It should be emphasized that the widely-practiced comprehensive soil erosion control measures such as check dam should be investigated to reduce the uncertainties of the estimation in the future.

\section{Conclusions}

This research identified the changes of hydro-meteorological factors in 1962-2008 and quantified the effects of climate change and LUCC on the streamflow in the Jihe watershed. We concluded that the streamflow presented a significant decreasing trend during 1962-2008 with a change point occurred in 1971. The streamflow dropped sharply in the 1990s and the M-K statistic value exceeded the $95 \%$ significance level since 1991. The annual streamflow for the period (1990s) was about $43 \%$ of the mean annual streamflow of the entire study period (1962-2008). Corresponding to the streamflow decline in 1990s was a marked rise in temperature and neither decline in precipitation nor decline in PET was observed for the same time. The 1990s was an important period of climatic change when the temperature showed a trend of a continuous increase with a change point occurred in 1994 while the precipitation decreased. Based on the land use type analysis, the watershed was dominated by slope cropland and grassland in the1970s while the area of terrace was very small. Terrace and grassland became the main land use types and forest cover to some extent increased because of the Grain for Green Project in the 1990s. The land use transition matrix shows that the greatest inter-conversion was the flow-out of the slope cropland to terrace. LUCC was the main reason for the rapid streamflow reduction with the contribution reaching $90.2 \%$ while the contribution of climate change to streamflow decline only accounted for $9.8 \%$. Although the analytical results between the elasticity method and linear regression model were not satisfactorily consistent, they both indicated that LUCC (human activity) was the major factor causing streamflow decline in the Jihe watershed from 1962 to 2008.

\section{Acknowledgements}

This study was funded by the National Natural Science Foundation of China (41501025, 51609083, 41401038, 51509089) and the 2016 Key Scientific Research Projects for Universities of Henan Province (16A170014). We sincerely thank the anonymous reviewers and editors for their valuable comments.

\section{References}

Al-Mukhtar M, Dunger V, Merkel B. 2014. Assessing the impacts of climate change on hydrology of the upper reach of the Spree River: Germany. Water Resources Management, 28(10): 2731-2749.

Ashraf Vaghefi S, Mousavi S J, Abbaspour K C, et al. 2014. Analyses of the impact of climate change on water resources components, drought and wheat yield in semi-arid regions: Karkheh river basin in Iran. Hydrological Processes, 28(4): 20182032.

Berti A, Tardivo G, Chiaudani A, et al. 2014. Assessing reference evapotranspiration by the Hargreaves method in north-eastern Italy. Agricultural Water Management, 140: 20-25.

Brown A E, Zhang L, McMahon T A, et al. 2005. A review of paired catchment studies for determining changes in water yield resulting from alterations in vegetation. Journal of Hydrology, 310(1-4): 28-61.

Chen J F, Li X B, Zhang M. 2005. Simulating the impacts of climate variation and land-cover changes on basin hydrology: a case study of the Suomo basin. Science in China Series D: Earth Sciences, 48(9): 1501-1509.

Chen S Y, Shi Y Y, Guo Y Z, et al. 2010. Temporal and spatial variation of annual mean air temperature in arid and semi-arid region in northwest China over a recent 46 year period. Journal of Arid Land, 2(2): 87-97.

Cuo L, Zhang Y X, Gao Y H, et al. 2013. The impacts of climate change and land cover/use transition on the hydrology in the upper Yellow River Basin, China. Journal of Hydrology, 502: 37-52.

Fan X G, Ma Z G, Yang Q, et al. 2015. Land use/land cover changes and regional climate over the Loess Plateau during 20012009. Part I: observational evidence. Climatic Change, 129(3-4): 427-440.

Fiseha B M, Setegn S G, Melesse A M, et al. 2014. Impact of climate change on the hydrology of upper Tiber River Basin using bias corrected regional climate model. Water Resources Management, 28(5): 1327-1343. 
Hu Y R, Maskey S, Uhlenbrook S, et al. 2011. Streamflow trends and climate linkages in the source region of the Yellow River, China. Hydrological Processes, 25(22): 3399-3411.

Li Q Y, Yu X X, Xin Z B, et al. 2013. Modeling the effects of climate change and human activities on the hydrological processes in a semi-arid watershed of Loess Plateau. Journal of Hydrologic Engineering, 18(4): 401-412.

Li X M, Li L H, Guo L P, et al. 2011. Impact of climate factors on runoff in the Kaidu River watershed: path analysis of 50-year data. Journal of Arid Land, 3(2): 132-140.

Li Z, Liu W Z, Zhang X C, et al. 2010. Assessing and regulating the impacts of climate change on water resources in the Heihe watershed on the Loess Plateau of China. Science China Earth Sciences, 53(5): 710-720.

Li Z, Liu W Z, Zhang X C, et al. 2011. Assessing the site-specific impacts of climate change on hydrology, soil erosion and crop yields in the Loess Plateau of China. Climatic Change, 105(1-2): 223-242.

Liang W, Bai D, Jin Z, et al. 2015. A study on the streamflow change and its relationship with climate change and ecological restoration measures in a sediment concentrated region in the Loess Plateau, China. Water Resources Management, 29(11): 4045-4060.

Liu C M, Li D F, Tian Y, et al. 2003. An application study of DEM based distributed hydrological model on macroscale watershed. Progress in Geography, 22(5): 437-445. (in Chinese)

Milly P C D, Dunne K A. 2002. Macroscale water fluxes 2. Water and energy supply control of their interannual variability. Water Resources Research, 38(10): 24-1-24-9, doi: 10.1029/2001WR000760.

Myronidis D, Stathis D, Ioannou K, et al. 2012. An integration of statistics temporal methods to track the effect of drought in a shallow Mediterranean Lake. Water Resources Management, 26(15): 4587-4605.

Nunes A N, de Almeida A C, Coelho C O A. 2011. Impacts of land use and cover type on runoff and soil erosion in a marginal area of Portugal. Applied Geography, 31(2): 687-699.

Perazzoli M, Pinheiro A, Kaufmann V. 2013. Assessing the impact of climate change scenarios on water resources in southern Brazil. Hydrological Sciences Journal, 58(1): 77-87.

Rodriguez-Iturbe I, Porporato A, Laio F, et al. 2001. Intensive or extensive use of soil moisture: plant strategies to cope with stochastic water availability. Geophysical Research Letters, 28(23): 4495-4497.

Schaake J C. 1990. From climate to flow. In: Waggoner P E. Climate Change and U.S. Water Resources. New York: John Wiley and Sons, 177-206.

Schilling K E, Chan K S, Liu H, et al. 2010. Quantifying the effect of land use land cover change on increasing discharge in the Upper Mississippi River. Journal of Hydrology, 387(3-4): 343-345.

Tang L X, Zhang Z Q, Wang X J, et al. 2010. Streamflow response to climate and landuse changes in Qingshui River watershed in the loess hilly-gully region of Western Shanxi Province, China. Chinese Journal of Plant Ecology, 34(7): 800-810. (in Chinese)

Wang G Q, Zhang J Y, He R M. 2006. Impacts of environmental change on runoff in Fenhe river basin of the middle Yellow River. Advances in Water Science, 17(6): 853-858. (in Chinese)

Xu X Y, Yang D W, Yang H B, et al. 2014. Attribution analysis based on the Budyko hypothesis for detecting the dominant cause of runoff decline in Haihe basin. Journal of Hydrology, 510: 530-540.

Xu Y P, Zhang X J, Ran Q H, et al. 2013. Impact of climate change on hydrology of upper reaches of Qiantang River Basin, East China. Journal of Hydrology, 483: 51-60.

Xu Z X, Li J Y, Liu C M. 2007. Long-term trend analysis for major climate variables in the Yellow River Basin. Hydrological Processes, 21(14): 1935-1948.

Yang H B, Yang D W. 2011. Derivation of climate elasticity of runoff to assess the effects of climate change on annual runoff. Water Resources Research, 47(7): W07526, doi: 10.1029/2010WR009287.

Yang H B, Qi J, Xu X Y, et al. 2014. The regional variation in climate elasticity and climate contribution to runoff across China. Journal of Hydrology, 517: 607-616.

Yang X L, Ren L L, Liu Y, et al. 2014. Hydrological response to land use and land cover changes in a sub-watershed of West Liaohe River Basin, China. Journal of Arid Land, 6(6): 678-689.

Zhan C S, Zeng S D, Jiang S S, et al. 2014. An integrated approach for partitioning the effect of climate change and human activities on surface runoff. Water Resources Management, 28(11): 3843-3858.

Zhang D, Liu X M, Liu C M, et al. 2013. Responses of runoff to climatic variation and human activities in the Fenhe River, China. Stochastic Environmental Research and Risk Assessment, 27(6): 1293-1301.

Zhang L, Dawes W R, Walker G R. 2001. Response of mean annual evapotranspiration to vegetation changes at catchment scale. Water Resources Research, 37(3): 701-708. 